\title{
Prevalence of diarrhoea and risk factors among children under five years old in Mbour, Senegal: a cross-sectional study
}

Sokhna Thiam 1,2,3, Aminata N. Diène ${ }^{3}$, Samuel Fuhrimann ${ }^{1,2}$, Mirko S. Winkler ${ }^{1,2}$, Ibrahima Sy ${ }^{4}$, Jacques A. Ndione ${ }^{4}$, Christian Schindler ${ }^{1,2}$, Penelope Vounatsou ${ }^{1,2}$, Jürg Utzinger ${ }^{1,2}$, Ousmane Faye ${ }^{5}$ and Guéladio Cissé $e^{1,2^{*}}$

\begin{abstract}
Background: Diarrhoeal diseases remain an important cause of mortality and morbidity among children, particularly in low- and middle-income countries. In Senegal, diarrhoea is responsible for $15 \%$ of all deaths in children under the age of five and is the third leading cause of childhood deaths. For targeted planning and implementation of prevention strategies, a context-specific understanding of the determinants of diarrhoeal diseases is needed. The aim of this study was to identify risk factors of diarrhoeal diseases in children under the age of five in Mbour, Senegal.
\end{abstract}

Methods: Between February and March 2014, a cross-sectional survey was conducted in four zones of Mbour to estimate the burden of diarrhoeal diseases (i.e. diarrhoea episodes in the 2 weeks preceding the survey) and associated risk factors. The zones covered urban central, peri-central, north peripheral and south peripheral areas. Overall, 596 households were surveyed by a questionnaire, yielding information on sociodemographic, environmental and hygiene behavioural factors. Univariable and multivariable logistic regression analyses were used to identify risk factors associated with the occurrence of diarrhoea.

Results: The reported prevalence of diarrhoea among children under the age of five during the 2 weeks preceding the survey was $26 \%$. Without adjustment, the highest diarrhoea prevalence rates were observed in the peri-central (44.8\%) and urban central zones (36.3\%). Multivariable regression revealed significant associations between diarrhoeal diseases and unemployment of mothers (adjusted odds ratio $[\mathrm{aO} R]=1.62,95 \%$ confidence interval [C]: 1.18-2.23), use of open bags for storing household waste ( $\mathrm{aOR}=1.75,95 \% \mathrm{Cl}: 1.00-3.02)$, evacuation of household waste in public streets $(\mathrm{aOR}=2.07,95 \% \mathrm{Cl}: 1.20-3.55)$, no treatment of stored drinking water $(\mathrm{aOR}=1.69,95 \% \mathrm{Cl}: 1.11-2.56)$ and use of shared toilets (aOR $=1.69,95 \% \mathrm{Cl}: 1.11-2.56)$.

Conclusion: We found a high prevalence of diarrhoea in children under the age of five in Mbour, with the highest prevalence occurring in the central and peri-central areas. These findings underscore the need for public health interventions to alleviate the burden of diarrhoea among vulnerable groups. Promotion of solid waste disposal and reduction of wastewater exposure should be implemented without delay.

Keywords: Children under five year-old, Cross-sectional survey, Diarrhoea, Multivariable logistic regression, Risk factor, Senegal

\footnotetext{
* Correspondence: gueladio.cisse@unibas.ch

${ }^{1}$ Swiss Tropical and Public Health Institute, P.O. BoxCH-4002 Basel, Switzerland

${ }^{2}$ University of Basel, P.O. BoxCH-4003 Basel, Switzerland

Full list of author information is available at the end of the article
} 


\section{Multilingual abstracts}

Please see Additional file 1 for translations of the abstract into the five official working languages of the United Nations.

\section{Background}

Diarrhoeal diseases remain among the most common causes of mortality and morbidity in children, particularly in low- and middle-income countries (LMICs). In 2013, of the 6.3 million children worldwide who died before they reached their fifth birthday, about half (3.2 million) died from infectious diseases, with diarrhoea killing more than 500,000 children [1]. By 2030, it is estimated that 4.4 million children under the age of five will die from infectious diseases annually and that $60 \%$ of those deaths will occur in sub-Saharan Africa [1]. Diarrhoea accounts for an estimated $3.6 \%$ of the global burden of disease, as expressed in disability-adjusted life years (DALYs) [2]. Although mortality from diarrhoea has declined considerably over the past 25 years globally, morbidity from diarrhoea in sub-Saharan Africa has not, as risk factors related to inadequate water, sanitation and hygiene (WASH), insufficient promotion of breastfeeding and malnutrition remain unacceptably high [3]. The rapid growth of African cities and associated overcrowding has been linked to outbreaks of diarrhoea, with children under the age of five among the most affected [4].

In Senegal, the Ministry of Health $(\mathrm{MoH})$ lists diarrhoea as the third leading cause of mortality and the second leading cause driving caregivers of children under 5 years old to seek medical consultation [5]. In 2013, according to Liu and colleagues, the total number of deaths among children under the age of five in the country was 28,648 , with 1866 deaths $(15 \%)$ due to diarrhoeal diseases $[1,6]$. In 2011, the Senegalese Demographic and Health Survey (DHS) reported that one in five children under the age of five suffered from diarrhoea during the 2 weeks preceding the survey (21\%) [7]. The 2014 DHS showed that prevalence of diarrhoea in this age group remained at the same level (19\%) [8].

Lack of access to clean water and improved sanitation is a major issue in the urban coastal area of Senegal, where 13.5 million people reside, accounting for $45 \%$ of the national population [9]. Rapid urbanisation in sub-Saharan Africa (including Senegal) over the past few decades has resulted in disorganised urban landscapes, where populations live in crowded conditions $[10,11]$. Urbanisation not only occurs in capital cities of LMICs, but also in secondary cities [12]. Indeed, half of the anticipated urban population increase in the coming years is expected to occur in secondary African cities and in smaller cities that connect the rural hinterlands of the sub-region [13-15]. The urbanisation trends in secondary cities merit focused attention due to the particular weaknesses and vulnerabilities of those contexts.
In Mbour, a secondary coastal city in Senegal, the population has grown from approximately 100,000 in 1988 to more than 220,000 in 2014 [16]. However, unofficial estimations by Mbour municipality leaders suggest that the current population might be as high as 700,000 , which is far above the projection for 2014 made by the National Agency of Statistics and Demography (ANSD) on the basis of 2002 census data. This massive increase in Mbour's population has also resulted in a spatial extension of $56 \%$ [17], the spread of urban slums and a lack of basic services pertaining to WASH and solid waste removal $[18,19]$. These conditions create a high risk of water-borne and gastrointestinal diseases, including diarrhoea [20]. Not surprisingly, Mbour was among the ten health districts in Senegal characterised by high numbers of diarrhoeal cases. To better understand the determinants of diarrhoea in this urban setting, data are needed to better understand the local epidemiology. Such data will be valuable for designing and implementing intervention and prevention strategies to reduce morbidity due to diarrhoea at the community level.

Here, we provide an overview of diarrhoea prevalence and risk factors among children under 5 years old in Mbour. Specifically, we determined the prevalence of selfreported diarrhoea and identified key risk factors among young children in this secondary city of Senegal.

\section{Methods \\ Study area}

The study was conducted in Mbour, a secondary coastal city in Senegal on the edge of the Atlantic Ocean (Fig. 1). The city lies approximately $19 \mathrm{~m}$ above sea level in the region of Thiès in western Senegal (latitude $14^{\circ} 41^{\prime} 6^{\prime \prime} \mathrm{N}$ and longitude $\left.16^{\circ} 96^{\prime} 9^{\prime \prime} \mathrm{W}\right)$, about $80 \mathrm{~km}$ south of the capital, Dakar. Administratively, the city is divided into 25 neighbourhoods. Mbour's health system consists of a hospital, a health centre and 10 health posts. The study area was stratified into four zones according to specific characteristics, namely: (i) urban central area (UCA); (ii) peri-central area (PCA); (iii) north peripheral area (NPA); and (iv) south peripheral area (SPA). The PCA, UCA, NPA and SPA cover areas of $7,4,8$ and $6 \mathrm{~km}^{2}$, respectively. The respective population sizes are 98,126, $48,011,53,894$ and 28,259.

The UCA is the original core of the city and includes the central neighbourhoods, the historic district and commercial centre, all with a type of traditional habitat. It is characterised by poor sanitation, high population density and overcrowding and is inhabited mostly by fishermen. The PCA is the first peri-urban area of the city, composed of regular and irregular neighbourhoods like Baye Deuk, an informal neighbourhood surrounding the core. The NPA and SPA comprise new neighbourhoods or peripheral 

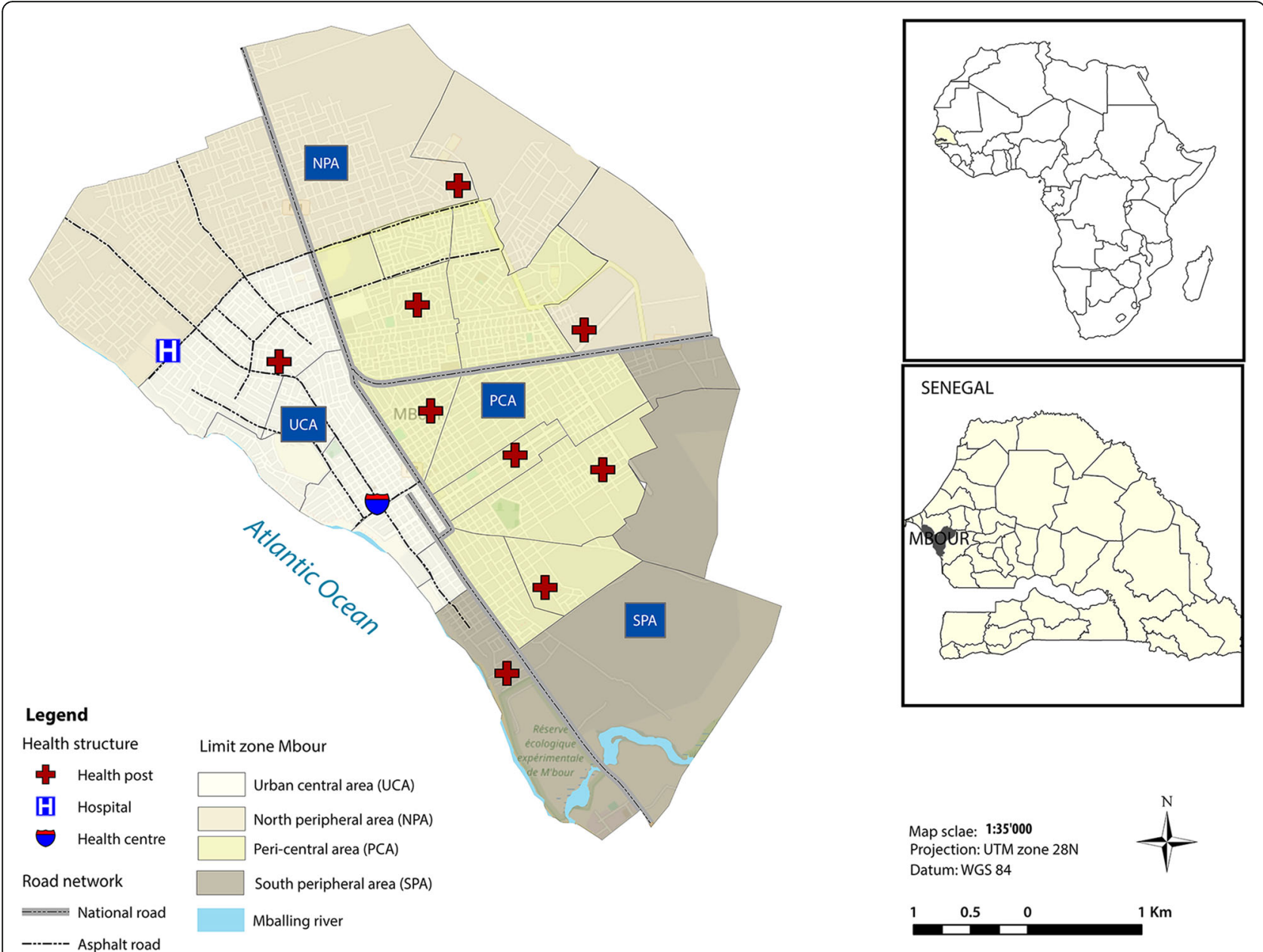

Fig. 1 Map showing Mbour in Senegal and the location of the four different zones

neighbourhoods. The NPA is marked by a modern habitat and better access to basic social services in some neighbourhoods, while the SPA is characterised by straw houses, a precarious socioeconomic status and a lack of access to safe drinking water. Most of the population in the SPA and NPA use water from traditional wells. These four zones were chosen to compare the prevalence and risk factors of diarrhoea related to living conditions, socioeconomic status, drinking water sources, sanitation facilities, hygiene and education levels.

\section{Outcome definition}

The primary outcome variable was the occurrence of diarrhoea during the 2-week period preceding the survey interview. For this purpose, the DHS definition of diarrhoea was applied, i.e. having three or more loose or liquid bowel movements over a 24-h period, as reported by the mother or caregiver of the child, at any point during the 2 weeks preceding the interview [8]. This definition is in line with that of the World Health Organization (WHO) [21].

\section{Household survey and study population}

A cross-sectional study was carried out between 2 February and 8 March 2014. As the prevalence of diarrhoea in Mbour had not been investigated in previous studies, we assumed an average prevalence rate of $26 \%$, based on data obtained from the DHS and National Survey on Food Security and Nutrition (ENSAN), representing the Thiès region where Mbour is located $[7,22]$. The sample size $(n)$ was calculated to achieve sufficient precision in estimating the prevalence of diarrhoea among children under 5 years, using the following formula: $n=Z^{2} \times \mathrm{p} \times(1-\mathrm{p}) \times c / r^{2}$ where: $Z$ equals $1.96, \mathrm{p}$ is the estimated prevalence of diarrhoea among children under 5 years (assumed to be 26\%), $r$ is the accepted margin of error (assumed to be 5\%) and $c$ is the design effect accounting for clustering of the data within households. Assuming $c=2$, a sample size of 600 households was calculated. Having divided the city into four zones (i.e. PCA, UCA, NPA and SPA), we determined the sample size of households proportionally to the population for each zone. We randomly selected clusters of equal size (25 households) within each zone. Overall, we surveyed 
24 clusters. These clusters were defined by the smallest administrative units, known as "district census". The final sample size was 596 households.

Households were eligible for inclusion in the survey if the following criteria were met: (i) presence of mother or caregiver; and (ii) presence of at least one child under the age of five. A structured questionnaire was administered for data collection. The questionnaire was inspired by the Multiple Indicators Cluster Survey (MICS) and by DHS questionnaires related to diarrhoea. The French language version of the questionnaire was translated into local language and then translated back into French to ensure accuracy. Four experienced investigators conducted interviews in the local language or in French, using a paper-based questionnaire. Investigators were trained to administer the interview, to follow data quality assurance procedures and to adhere to principles of ethical conduct in human research. The survey questionnaire was pre-tested in a neighbourhood of Mbour that was not otherwise considered, to ensure that questions were properly understood by the local communities. In the pilot study, ten households were interviewed and any observed shortcomings in the instruments were corrected before the start of data collection. The pre-test also provided crucial information on the validity and usefulness of the data collected.

Independent variables included the following: (i) sociodemographic information (zone, mother's age, family size, number of children under the age of five in the household, mother's or caregiver's educational level); (ii) socioeconomic status (occupation); (iii) environmental and behavioural indicators (availability of a toilet, type of toilet, drinking water source, solid waste and wastewater disposal, personal hygiene); and (iv) occurrence of diarrhoea. Socioeconomic status of the households was classified as either "richest", "middle" or "poorest", based on a cumulative standardised assets score, which was calculated using principal component analysis. All asset variables considered were dichotomous (e.g. presence or absence of radio).

\section{Statistical analysis}

Statistical analysis was performed in Stata version 13.0 (Stata Corporation; College Station, United States of America). Descriptive statistics were used to summarise the study variables. Associations between outcome and independent variables were expressed by their odds ratios (ORs) and $95 \%$ confidence intervals (CIs). Mixed univariable and multivariable logistic regression models with random intercepts for households were used to quantify the effects of the risk factors on the diarrhoea outcome and to compare differences in diarrhoea prevalence between the zones. Models were compared using likelihood ratio tests (LRTs). To reduce the number of parameters and to improve precision of the estimates of the final models, we only considered variables that had a $P$-value below 0.2 in the univariable analysis (using LRT) for the multivariable analysis. Statistical significance was defined at the level of $5 \%$.

\section{Results \\ Sociodemographic characteristics of the surveyed households}

A total of 1136 children under the age of five $(50.8 \%$ males) from 596 households participated in the survey conducted in four zones of Mbour, in early 2014 (Fig. 2). Demographic and socioeconomic characteristics of the surveyed households are summarised in Table 1 . The median age of the respondents was 30 years. Parental ages presented in Table 1 are for those parents with complete questionnaire results. Most of the mothers were married $(93.5 \% ; n=275)$. The primary occupation was housewife (56.6\%; $n=167)$. Almost half of the mothers had no formal education $(45.6 \% ; n=272)$. The mean household size was 8.7 (standard deviation (SD): 4.8) individuals.

\section{Access to water and sanitation}

As shown in Table 1, tap water at home was the most commonly used drinking water source $(61.7 \%$; $n=368)$, followed by water from public taps $(25.5 \% ; n=152)$, well water $(8.6 \% ; n=51)$ and other sources $(4.2 \% ; n=25)$. In the UCA, $83.4 \%(n=146)$ had their own tap water at home, followed by the NPA $(64.9 \%, n=63)$, PCA $(55.8 \%, n=153)$ and SPA $(12.0 \%, n=6)$.

Two thirds of the households $(69.6 \% ; n=415)$ stored drinking water and $16.4 \%$ of them $(n=98)$ treated the stored water prior to consumption. Among the households that treated their water prior to storing, 69 (70.4\%) used chlorination, 22 (22.4\%) used filtration, and 7 (7.1\%) employed other methods. Most households (97.3\%; $n=580$ ) had a toilet facility at home, while the remaining 16 households had no access to sanitation facilities (2.7\%). Among households with a toilet, 522 (90.0\%) had a septic tank, 222 (38.3\%) shared toilet facilities and only 7 (1.2\%) households were connected to a sewer. Two hundred and one households $(33.7 \%)$ reported no kitchen at home. Most of them $(63.7 \% ; n=128)$ prepared their food in the yard of the house, while $18.9 \%(n=38)$ prepared food in a covered space provided for cooking in the yard of the house and $17.4 \%(n=35)$ in a corridor in the residence.

\section{Reported prevalence of diarrhoea among children under the age of five}

Diarrhoea prevalence among children under the age of five was estimated based on the number of children who reportedly had diarrhoea during the 2 weeks preceding the interview as the numerator and the overall number of children in the sample as the denominator. Diarrhoeal cases occurring within the 2 weeks preceding the interview were reported for one in four children, giving an overall prevalence of $26.1 \%(n=295)$. Prevalence was 


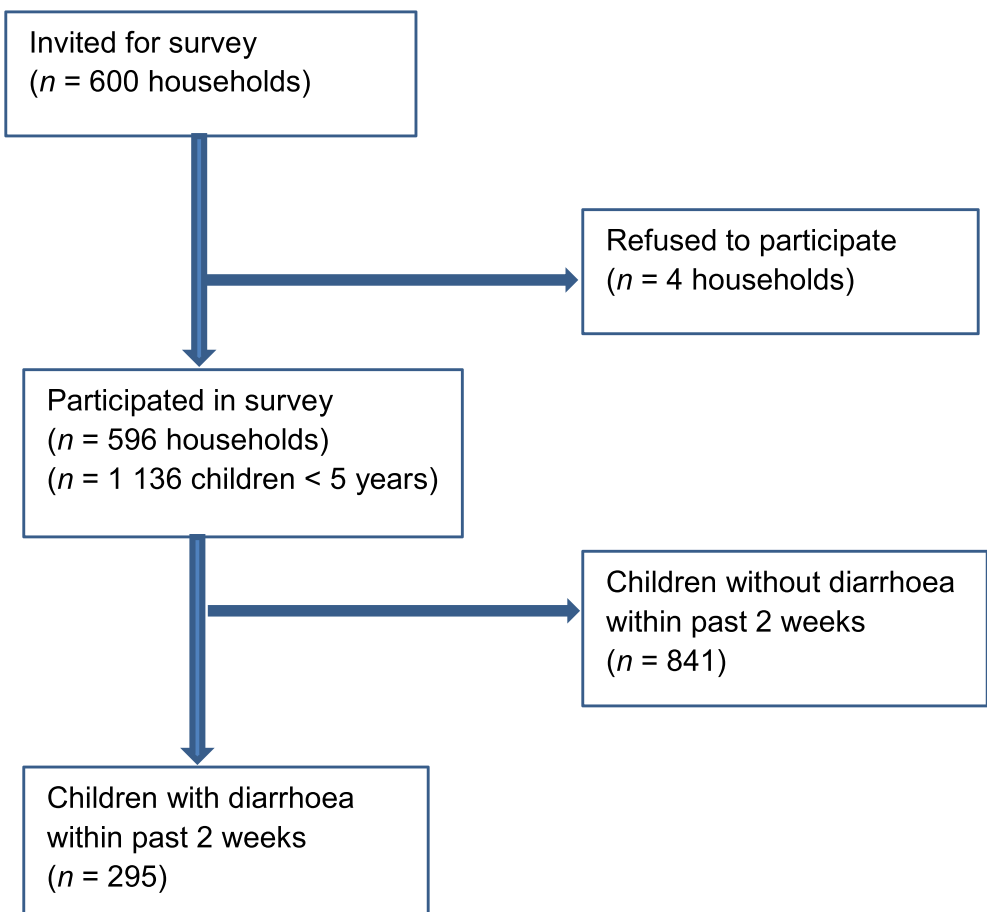

Fig. 2 Summary of surveyed household and results of reported diarrhoea cases by age categories in Mbour, Senegal, 2014

slightly higher among girls than boys $(27.6 \%$ and $24.4 \%$, respectively), but this difference was not statistically significant $(P=0.22)$. Adjusted diarrhoea prevalence among children under the age of five did not show a significant difference between zones, with the highest rate observed in the UCA (26.9\%) and the lowest rate in the SPA (17.1\%). Without adjusting for other variables, the highest diarrhoea prevalence was observed in the PCA (44.8\%) and the second highest in the UCA (36.3\%), as shown in Figs. 3 and 4. The analysis stratified by age group showed a higher prevalence of diarrhoea in the oldest age group (24-59 months), while the lowest diarrhoea prevalence was observed among children under 12 months (Fig. 3). Diarrhoea prevalence, stratified by age group and zone, is shown in Fig. 5. In this analysis, the highest prevalence was observed among children 12-23 months in the PCA. The highest prevalence among children $<12$ months was observed in the UCA and NPA. The proportion of children having more than one diarrhoea event during the 2 weeks immediately preceding the survey was $30 \%$.

\section{Household risk factors associated with diarrhoea}

The results from the univariable and multivariable logistic regression analyses are presented in Tables 2 and 3. After adjustment for potential confounders, diarrhoea among children under the age of five was significantly associated with: (i) mother's unemployment (adjusted $(\mathrm{aOR})=1.62,95 \% \mathrm{CI}: 1.18-2.23)$; (ii) sharing the toilet with other households $(\mathrm{aOR}=1.69,95 \% \mathrm{CI}$ : 1.11-2.56); (iii) use of unconventional bag (open bag) for storing household solid waste $(\mathrm{aOR}=1.75,95 \% C I: 1.00-3.02)$; note that solid waste comprises garbage originating from private homes or apartments (also called domestic waste or residential waste); (iv) households with more than one child under the age of five $(\mathrm{aOR}=2.86,95 \% \mathrm{CI}$ : $1.70-4.80$ and $\mathrm{aOR}=1.55,95 \% \mathrm{CI}: 1.00-2.40)$; (v) evacuation of household domestic wastewater in public street $(\mathrm{aOR}=2.07,95 \% C I: 1.20-3.55)$; and (vi) no treatment of stored drinking water $(\mathrm{aOR}=1.69,95 \% \mathrm{CI}$ : $1.11-$ 2.56). Conversely, mother's above 40 years $(\mathrm{aOR}=0.38$, 95\% CI: $0.22-0.65)$ and "middle" $(\mathrm{aOR}=0.64,95 \% \mathrm{CI}$ : $0.41-0.98)$ and "richest" ( $\mathrm{aOR}=0.62,95 \% \mathrm{CI}: 0.42-0.90)$ socioeconomic status were negatively associated with the occurrence of diarrhoea.

\section{Discussion}

In this study, we compared diarrhoea prevalence (recall period: 2 weeks) and risk factors among children under the age of five in four zones of Mbour, a medium-size town in Senegal. We found that the 2-week, caregiver-reported prevalence of diarrhoea among children under 5 years was $26 \%$, which is slightly above the rate reported for the same age group in the 2014 Senegalese DHS (19\%) [7]. However, our rate is below that reported in the ENSAN 2013 survey report (32\%) for the Thiès region [22]. It is also lower than the $35 \%$ prevalence among children under 5 years previously reported in Kaédi, Mauritania by Touray and colleagues (2012) [23]. Other studies in secondary cities of 
Table 1 Characteristics of the households surveyed $(n=596)$ in four zones of Mbour, Senegal, in early 2014

\begin{tabular}{|c|c|c|c|c|c|c|}
\hline Variables & $\begin{array}{l}\text { UCA }(N=175) \\
n(\%)\end{array}$ & $\begin{array}{l}\text { PCA }(N=324) \\
n(\%)\end{array}$ & $\begin{array}{l}\text { NPA }(N=47) \\
n(\%)\end{array}$ & $\begin{array}{l}\text { SPA }(N=50) \\
n(\%)\end{array}$ & $\begin{array}{l}\text { Overall }(N=596) \\
n(\%)\end{array}$ & $P$-value \\
\hline \multicolumn{7}{|l|}{ Caretaker characteristics } \\
\hline Age in years & & & & & & 0.065 \\
\hline$<25$ & $24(15.9)$ & $47(18.9)$ & $20(22.5)$ & $8(19.5)$ & $99(18.7)$ & \\
\hline $25-29$ & $39(25.8)$ & $52(20.9)$ & $13(14.6)$ & $2(4.9)$ & $106(20.0)$ & \\
\hline 30-39 & $55(36.4)$ & $100(40.1)$ & $34(38.2)$ & $15(36.6)$ & $204(38.5)$ & \\
\hline$\geq 40$ & $33(21.8)$ & $50(20.1)$ & $22(24.7)$ & $16(39.0)$ & $121(22.8)$ & \\
\hline Educational level & & & & & & $<0.001$ \\
\hline Never went to school & $67(38.3)$ & $133(48.5)$ & $43(44.3)$ & $29(58.0)$ & $272(45.6)$ & \\
\hline Primary school & $81(46.3)$ & $70(25.6)$ & $32(33.0)$ & $9(18.0)$ & $192(32.2)$ & \\
\hline Secondary education or higher ${ }^{a}$ & $27(15.4)$ & $71(25.9)$ & $22(22.7)$ & $12(24.0)$ & $132(22.2)$ & \\
\hline \multicolumn{7}{|l|}{ Household characteristics } \\
\hline Number of household members & & & & & & $<0.001$ \\
\hline$<5$ members & $25(14.3)$ & $43(15.7)$ & $20(20.6)$ & $6(12.0)$ & $94(15.7)$ & \\
\hline 5-7 members & $31(17.7)$ & $103(37.6)$ & $48(49.5)$ & $14(28.0)$ & $196(32.9)$ & \\
\hline 8-10 members & $40(22.9)$ & $70(25.5)$ & 19 (19.6) & $15(30.0)$ & $144(24.2)$ & \\
\hline$\geq 11$ members & $79(45.1)$ & $58(21.2)$ & $10(10.3)$ & $15(30.0)$ & $162(27.2)$ & \\
\hline Number of children $<5$ years in the house & & & & & & $<0.001$ \\
\hline$<2$ & $64(36.6)$ & $129(47.1)$ & $52(53.6)$ & $24(48.0)$ & $269(45.1)$ & \\
\hline 2 to 3 & $77(44.0)$ & $126(46.0)$ & $42(43.3)$ & $25(50.0)$ & $270(45.3)$ & \\
\hline $4+$ & $34(19.4)$ & $19(6.9)$ & $3(3.1)$ & $1(2.0)$ & $57(9.6)$ & \\
\hline Socio-economic status & & & & & & $<0.001$ \\
\hline Poorest & $9(5.2)$ & $89(32.5)$ & $24(24.7)$ & $26(52.0)$ & $148(24.9)$ & \\
\hline Middle & 55 (31.6) & $54(19.7)$ & $24(24.7)$ & $16(32.0)$ & $149(25.0)$ & \\
\hline Richest & $110(63.2)$ & $131(47.8)$ & $49(50.5)$ & $8(16.0)$ & $298(50.1)$ & \\
\hline Drinking water sources & & & & & & $<0.001$ \\
\hline Tap water in the house & $146(83.4)$ & $153(55.8)$ & $63(64.9)$ & $6(12.0)$ & $368(61.7)$ & \\
\hline Public tap & $24(13.7)$ & $95(34.7)$ & $20(20.6)$ & $13(26.0)$ & $152(25.5)$ & \\
\hline Well water & $2(1.1)$ & $9(3.2)$ & $13(13.4)$ & $27(54.0)$ & $51(8.6)$ & \\
\hline Others $^{b}$ & $3(1.7)$ & $17(6.2)$ & $1(1.0)$ & $4(8.0)$ & $25(4.2)$ & \\
\hline Water storage & & & & & & $<0.001$ \\
\hline No & $67(38.3)$ & $58(21.2)$ & $38(39.2)$ & $18(36.0)$ & $181(30.4)$ & \\
\hline Yes & $108(61.7)$ & $216(78.8)$ & $59(60.8)$ & $32(64.0)$ & 415 (69.6) & \\
\hline Toilet availability & & & & & & $<0.001$ \\
\hline No & $2(1.1)$ & $6(2.2)$ & $1(1.0)$ & $7(14.0)$ & $16(2.7)$ & \\
\hline Yes & $173(98.9)$ & $268(97.8)$ & $96(99.0)$ & $43(86.0)$ & $580(97.3)$ & \\
\hline Type of toilet facilities & & & & & & $<0.001$ \\
\hline Sewer & $4(2.3)$ & $2(0.7)$ & $1(1.0)$ & 0 & $7(1.2)$ & \\
\hline Toilet with pit & $166(94.9)$ & $227(84.7)$ & 91 (94.8) & $38(88.4)$ & $522(90.0)$ & \\
\hline Traditional latrine & $3(1.7)$ & $39(14.6)$ & $4(4.2)$ & $5(11.6)$ & $51(8.8)$ & \\
\hline Toilet shared with others households & & & & & & $<0.001$ \\
\hline
\end{tabular}

No

Yes
$112(64.7) \quad 145(54.1)$
$66(68.8)$

$35(81.4)$

$358(61.7)$

$30(31.2)$

8 (18.6) 
Table 1 Characteristics of the households surveyed $(n=596)$ in four zones of Mbour, Senegal, in early 2014 (Continued)

\begin{tabular}{|c|c|c|c|c|c|c|}
\hline No kitchen available in the house & $52(29.7)$ & $102(37.2)$ & $21(21.6)$ & $26(52.0)$ & $201(33.7)$ & $<0.001$ \\
\hline \multicolumn{7}{|l|}{ Behavioural characteristics } \\
\hline Duration of storage & & & & & & 0.233 \\
\hline One day & $54(57.5)$ & $108(54.5)$ & $32(56.1)$ & $14(43.7)$ & $208(54.6)$ & \\
\hline Two days & $22(23.4)$ & $45(22.7)$ & $12(21.1)$ & $15(46.9)$ & $94(24.7)$ & \\
\hline Three days & $10(10.6)$ & $32(16.2)$ & $8(14.0)$ & $1(3.1)$ & $51(13.4)$ & \\
\hline More than four three days & $8(8.5)$ & $13(6.6)$ & $58.8)$ & $2(6.2)$ & $28(7.3)$ & \\
\hline Treatment water stored & & & & & & $<0.001$ \\
\hline Yes & $21(12.0)$ & $36(13.1)$ & $18(18.6)$ & $23(46.7)$ & $98(16.4)$ & \\
\hline
\end{tabular}

Bold $p$-value means significant difference between zones

${ }^{a}$ carter water seller and at the neighbour

${ }^{b} \mathrm{UCA}=$ Urban central area

${ }^{\mathrm{C}} \mathrm{PCA}=$ Peri-central area

${ }^{\mathrm{d}} \mathrm{NPA}=$ North peripheral area

${ }^{\text {e }} \mathrm{SPA}=$ South peripheral area

sub-Saharan Africa reported lower rates: $23.6 \%$ in a 2008 survey in Nouakchott, Mauritania; 14\% in 2006 in Yopougon, Côte d'Ivoire; and 13.5\% in 2010 in other districts of Nouakchott, Mauritania [23-27]. The high prevalence of diarrhoea in urban Senegal found in the present study was observed in the cold, dry season between February and March, the period of the harmattan, during which most diarrhoea cases and deaths due to rotavirus infection had previously been reported [10]. A study conducted in Burkina Faso during the cold, dry season (December 2009-February 2010) found a rotavirus prevalence of $63.8 \%$ among children under the age of five. The same study showed that up to $90 \%$ of all diarrhoea cases in this population group were related to rotavirus [28]. In view of these findings, more attention should be given to exploring diarrhoea seasonality and the influence of climatic parameters, in order to more effectively prevent and manage diarrhoea in urban settings in Senegal and elsewhere in sub-Saharan Africa.

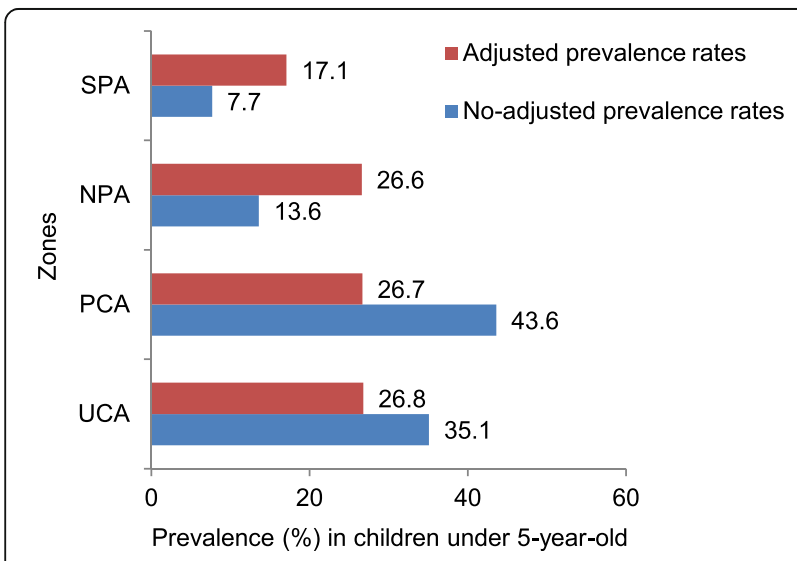

Fig. 3 Diarrhoeal prevalence rates by zone before and after adjustment for individual factors in Mbour, Senegal, 2014
According to our study, diarrhoeal prevalence was highest in the PCA (44.8\%), which was almost nine times higher than that in the SPA (5.1\%). Hence, there is considerable spatial heterogeneity of diarrhoea prevalence, which might partially be explained by differences in the distribution of risk factors across zones, such as living conditions, population density, socioeconomic status and WASH conditions.

We also found that diarrhoea was reported slightly more often among girls compared to boys. In contrast, diarrhoea was more frequent among boys in a study from Sudan [29]. Our finding might be explained by the cultural practices in Senegal, where there is an overt preference for boys over girls that might also affect how mothers or caregivers take care of children. For example, the 2014 Senegalese DHS indicates that care for diarrhoea concerns was sought more frequently for boys (36\%) than for girls (29\%) [8]. This suggests that boys suffer more frequently from diarrhoea compared to girls, unless there is a tendency to take girls to the doctor less often.

In our study, the prevalence of diarrhoea was highest in the age group $24-59$ months (51.5\%). This finding is in contrast to results from a study in Burkina Faso, where children under the age of 12 months had the highest rate of diarrhoea $(44 \%)[28,30]$. However, in the urban slums of Senegal, children aged $2-5$ years are likely to have a high risk of exposure to diarrhoeal pathogens because they have considerable independence. They are often highly mobile and play unsupervised within the community environment, where there is a high level of contamination.

Our study showed that the risk of diarrhoea was significantly associated with the mother's occupation (i.e. housewife was associated with higher diarrhoea risk compared to those working in the private or public sector). This finding is consistent with other reports, which found that parental occupation was associated 


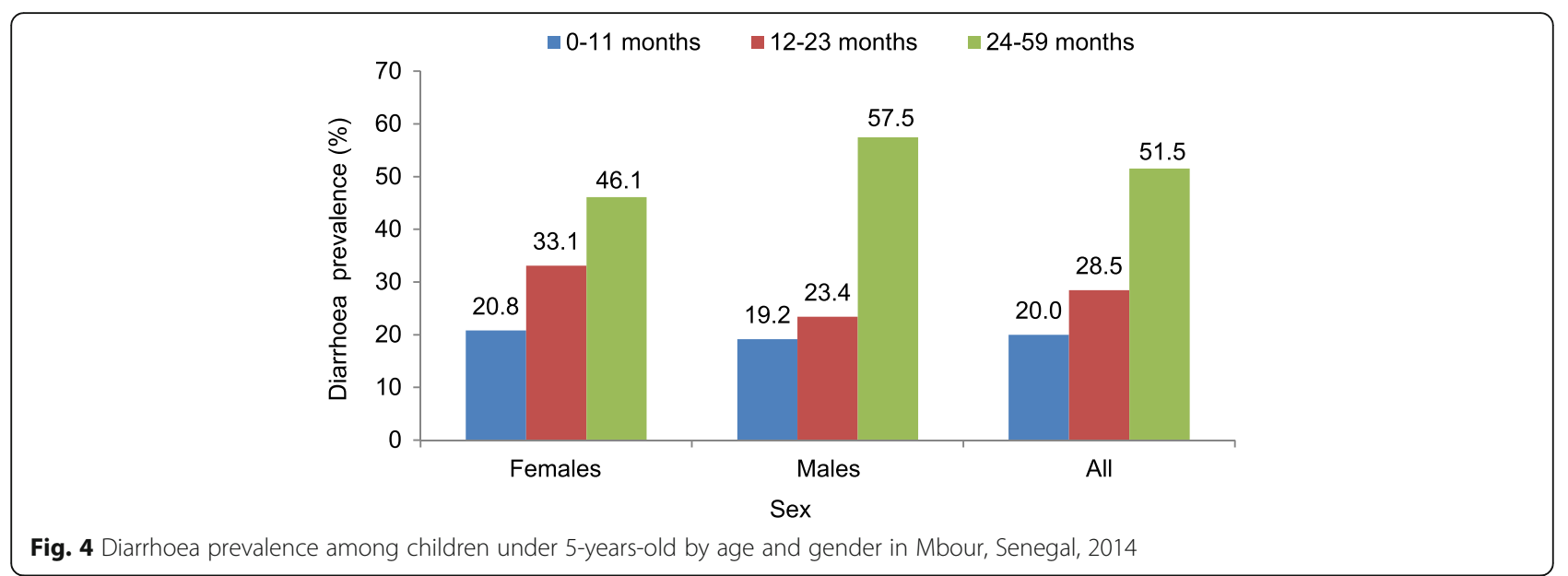

with diarrhoeal occurrence [31, 32]. Although socioeconomic status (middle and poorest) showed a significant association with the occurrence of diarrhoea in the bivariate analysis, it was not significant when other variables were included. In the multivariate analyses, we found that children living in better off households were less likely to have diarrhoea compared to their lower wealth counterparts. A likely explanation of this observation is that wealth is associated with better access to household amenities and facilities, including those related to better hygiene and environmental health, which might reduce the risk of diarrhoea. In addition, wealth allows parents to use health services more frequently [33, 34]. However, Root suggested that wealthy parents may be unable to reduce the risk of diarrhoea due to factors beyond their control, such as contaminated community environment or lack of water [35]. However, many other studies indicate that socioeconomic factors are strongly associated with the occurrence of diarrhoea; this appears to confirm the social determinants of health $[36,37]$.

The presence of two or more children under the age of five living in the same household was significantly associated with the occurrence of diarrhoea. This observation is consistent with a number of cross-sectional studies conducted in Nigeria and Cameroon [38-40]. These findings indicate that a large number of children residing in the same household is a predictor of diarrhoea among children under the age of five. More than two children in this age range in a single household probably means that contact with potential pathogens is more frequent than in households with only one or two young children [38]. This difference could be due to the challenges of taking care of multiple young children. It follows, then, that longer spacing between births and exclusive breastfeeding in the first 2 years of life might have a positive impact on diarrhoea prevention.

We did not find a significant association between drinking water sources and the occurrence of diarrhoea. This might be explained by the very small differences across the sampled households in terms of drinking water sources. In urban Africa, there are multiple sources of drinking water (e.g. well, tap water at home and public taps). Even if a household has a water connection at home, an inhabitant might need to go to the public tap or use

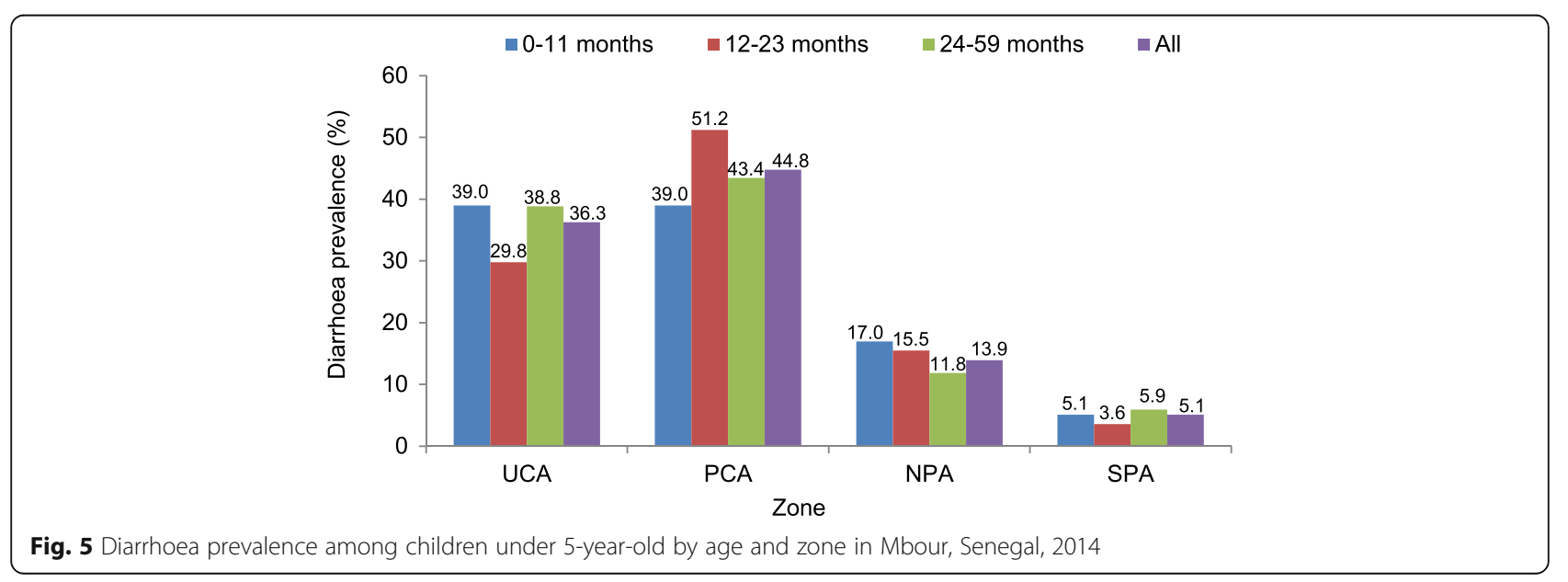


Table 2 Results of univariate logistic regression for diarrhoea risk factors in Mbour, Senegal, 2014

\begin{tabular}{|c|c|c|c|c|c|c|}
\hline \multicolumn{2}{|c|}{ Two weeks diarrhoea prevalence $N($ total $)=1136 / N($ cases $)=295$} & \multirow{2}{*}{$\begin{array}{l}\text { Diarrhoea } \\
N(\%)\end{array}$} & \multirow{2}{*}{$\begin{array}{l}\text { Healthy } \\
N(\%)\end{array}$} & \multicolumn{3}{|c|}{ Univariate logistic regression* } \\
\hline & & & & $O R$ & $95 \% \mathrm{Cl}$ & $P$-value \\
\hline \multicolumn{7}{|c|}{ 1.Socio-demographic and socioeconomic determinants of diarrhoea } \\
\hline \multirow[t]{4}{*}{ Age (in years) } & $<25$ & $62(22.3)$ & $127(17.1)$ & Reference & & $<0.001$ \\
\hline & $25-29$ & $71(26.7)$ & $159(21.4)$ & 0.91 & $0.61-1.38$ & 0.672 \\
\hline & $30-39$ & $106(39.8)$ & $232(39.3)$ & 0.74 & $0.51-1.08$ & 0.123 \\
\hline & $\geq 40$ & $27(10.1)$ & $165(22.2)$ & 0.33 & $0.20-0.56$ & $<0.001$ \\
\hline \multirow[t]{3}{*}{ Household's socioeconomic status } & Richest & $148(50.3)$ & $438(52.1)$ & 1.20 & $0.85-1.69$ & 0.301 \\
\hline & Middle & $58(19.7)$ & $206(24.5)$ & Reference & & $>0.053$ \\
\hline & Poorest & $88(30.0)$ & $197(23.4)$ & 1.58 & $1.07-2.33$ & 0.019 \\
\hline \multirow[t]{2}{*}{ Occupational status } & Employed & $128(43.4)$ & $482(57.3)$ & Reference & & \\
\hline & Unemployed & $167(56.6)$ & $359(42.7)$ & 1.75 & $1.34-2.29$ & $<0.001$ \\
\hline \multirow[t]{2}{*}{ Marital status } & Married & $275(93.5)$ & $765(91.2)$ & Reference & & 0.194 \\
\hline & Unmarried & $19(6.5)$ & $74(8.8)$ & 0.71 & $0.42-1.20$ & 0.207 \\
\hline \multirow[t]{4}{*}{ Number of household members } & $<5$ & $45(15.3)$ & $86(10.2)$ & 1.78 & $1.17-2.73$ & 0.008 \\
\hline & 5 to 7 & $87(29.5)$ & $224(26.6)$ & 1.32 & $0.95-1.85$ & 0.101 \\
\hline & 8 to 10 & $65(22.0)$ & $197(23.4)$ & 1.12 & $0.78-1.61$ & 0.522 \\
\hline & $\geq 11$ & $98(33.2)$ & $334(39.7)$ & Reference & & 0.049 \\
\hline \multirow[t]{3}{*}{ Number of children $<5$ years in the house } & $<2$ & $92(31.2)$ & $177(21.0)$ & 2.13 & $1.44-3.15$ & $<0.001$ \\
\hline & 2 to 3 & $150(50.8)$ & $447(53.2)$ & 1.37 & $0.97-1.95$ & 0.077 \\
\hline & $\geq 4$ & $53(18.0)$ & $217(25.8$ & Reference & & $<0.001$ \\
\hline \multicolumn{7}{|c|}{ 2.Environmental exposure variables associated with diarrhoea } \\
\hline \multirow[t]{3}{*}{ Type of toilet in the house } & Toilet with pit & $254(88.2)$ & $744(90.7)$ & Reference & & 0.035 \\
\hline & Latrine traditional & $25(8.7)$ & $69(8.4)$ & 1.06 & $0.66-1.71$ & 0.808 \\
\hline & Sewer network & $9(3.1)$ & $7(0.8)$ & 3.76 & $1.38-10.21$ & 0.009 \\
\hline \multirow[t]{3}{*}{ Storage of household solid waste } & Others ${ }^{* *}$ & $24(8.1)$ & $99(11.8)$ & Reference & & 0.058 \\
\hline & Pail/basin & $104(35.3)$ & $326(38.8)$ & 1.32 & $0.80-2.16$ & 0.279 \\
\hline & Open bag & $167(56.6)$ & $416(49.4)$ & 1.66 & $1.02-2.68$ & 0.040 \\
\hline \multirow[t]{2}{*}{ Toilet shared with others households } & Yes & $119(41.3)$ & $270(32.9)$ & 1.43 & $1.09-1.89$ & $<0.001$ \\
\hline & No & $169(58.68)$ & $550(67.1)$ & Reference & & $<0.001$ \\
\hline \multirow[t]{4}{*}{ Duration of storage } & Two days & $38(20.0)$ & $157(28.7)$ & Reference & & $<0.001$ \\
\hline & One day & $113(59.4)$ & $290(53.1)$ & 1.61 & $1.06-2.44$ & 0.025 \\
\hline & Three days & $29(15.3)$ & $64(11.7)$ & 1.87 & $1.07-3.29$ & 0.029 \\
\hline & More than three days. & $10(5.3)$ & $35(6.4)$ & 1.18 & $0.54-2.59$ & 0.689 \\
\hline \multicolumn{7}{|c|}{ 3.Behavioural related risk factor for diarrhoea } \\
\hline \multirow[t]{2}{*}{ Handwashing after work } & No & $243(82.4)$ & $613(72.9)$ & Reference & & \\
\hline & Yes & $52(17.6)$ & $228(27.1)$ & 0.57 & $0.41-0.80$ & $<0.001$ \\
\hline
\end{tabular}

Bold significant $p$-value $<0.05$ derived from the multivariate regression

${ }^{*}$ Odds ratio $(O R)$, confidence interval $(C l)$ and $P$-value derived from univariate logistic regression based on likelihood ratio test, overall significant $P$-value of the models are indicated in bold letter. ${ }^{* *}$ Others including half metal drum, plastic vacant lost or illegal dumping etc

well water due to recurrent cuts in the network. A study in southwest Ethiopia did not find a significant association between drinking water sources and the risk of diarrhoea either [41]. In contrast, two different studies from Ethiopia found that water sources are an important environmental predictor of diarrhoea morbidity [42, 43]. We found that the lack of treatment of stored drinking water was positively associated with the prevalence of diarrhoea.

We found that diarrhoea occurrence was not significantly associated with the presence of a toilet. This finding is in line with a recent study from Ethiopia, where no association was found between sanitary facilities and 
Table 3 Multivariate analysis of risk factors of diarrhoea among children < 5 years old in Mbour, Senegal, 2014

\begin{tabular}{|c|c|c|c|c|}
\hline \multicolumn{2}{|c|}{ Two weeks diarrhoea prevalence $N($ total $)=1136 / N($ cases $)=295$} & \multicolumn{3}{|c|}{ Multivariate logistic regression* } \\
\hline & & $\mathrm{aOR}$ & $95 \% \mathrm{Cl}$ & $P$-value \\
\hline \multirow[t]{4}{*}{ Age (in years) } & $<25$ & 1.00 & & \\
\hline & $25-29$ & 0.95 & $0.62-1.43$ & 0.802 \\
\hline & $30-39$ & 0.73 & $0.46-1.15$ & 0.178 \\
\hline & $\geq 40$ & 0.38 & $0.22-0.65$ & $<0.001 * *$ \\
\hline \multirow[t]{2}{*}{ Occupational status } & Employed & 1.00 & & \\
\hline & Unemployed & 1.62 & $1.18-2.23$ & $0.003^{* *}$ \\
\hline \multirow[t]{3}{*}{ Household's socioeconomic status } & Richest & 0.62 & $0.42-0.90$ & $0.013^{* *}$ \\
\hline & Middle & 0.64 & $0.41-0.98$ & $0.041^{* *}$ \\
\hline & Poorest & 1.00 & & \\
\hline \multirow[t]{3}{*}{ Number of children $<5$ years in the house } & $<2$ & 2.86 & $1.70-4.80$ & $<0.001^{* *}$ \\
\hline & 2 to 3 & 1.55 & $1.00-2.40$ & $0.035^{* *}$ \\
\hline & $\geq 4$ & 1.00 & & \\
\hline \multirow[t]{2}{*}{ Toilet shared with others households } & Yes & 1.69 & $1.11-2.56$ & $0.014^{* *}$ \\
\hline & No & 1.00 & & \\
\hline \multirow[t]{3}{*}{ Domestic wastewater disposal } & Dustbin & 1.00 & & \\
\hline & Pit & 0.96 & $0.62-1.49$ & 0.868 \\
\hline & Public street & 2.07 & $1.20-3.55$ & $0.009^{* *}$ \\
\hline \multirow[t]{3}{*}{ Storage of household solid waste } & Others & 1.00 & & \\
\hline & Pail/basin & 1.67 & $0.94-2.97$ & 0.080 \\
\hline & Open bag & 1.75 & $1.00-3.02$ & $0.046^{* *}$ \\
\hline \multirow[t]{2}{*}{ Treatment of drinking water stored } & Yes & 1.00 & & \\
\hline & No & 1.69 & $1.11-2.56$ & $0.014^{* *}$ \\
\hline
\end{tabular}

the occurrence of diarrhoea [41]. Conversely, another study from Ethiopia found that the availability of a latrine was negatively associated with diarrhoea after controlling for potential confounding factors [44]. The type of toilet showed a significant association with the occurrence of diarrhoea in our bivariate analyses. Rather unexpectedly, the association became insignificant when other variables were included in the multivariate analyses. We found that sharing a toilet with other households was associated with a high risk of diarrhoea.

Our study showed that the use of open bags for storing household solid waste was significantly associated with the prevalence of diarrhoea. In a study carried out in Ibadan, Nigeria, indiscriminate disposal of solid waste was significantly associated with a high rate of diarrhoea [45]. Studies in Ethiopia also revealed that open disposal of waste around the house was a risk factor for diarrhoea [26, 46]. We also found that evacuation of domestic wastewater from households into public streets was significantly associated with the risk of diarrhoea. The likely explanation for these results is that inappropriate disposal of solid waste and evacuation of wastewater in public streets create breeding sites for insects, which may spread diarrhoeal pathogens from the open waste to water or food.

Evacuation of human excreta into septic tanks conferred an increased risk of diarrhoea but these associations were not statistically significant, which may be due to its rare occurrence. We also found that mother's age (i.e. 40 years and above) significantly reduced the risk of children's diarrhoea. This finding might be explained by greater experience in childcare, hygiene and feeding practices with age.

Our findings support the 'urban health penalty' hypothesis, which posits that the poor in urban areas are pushed to marginal areas, where environmental health conditions are not suitable for health. This issue is particularly pronounced in secondary cities, where access to clean water and improved sanitation, and socioeconomic conditions more broadly, have been compromised by populations moving into urban areas that are unregulated and poorly managed. Such conditions might result 
in urban slums that are characterised by inadequate safe water supply, lack of drainage and sewage networks and the absence of sanitation and solid waste removal.

\section{Limitations}

Our study has several limitations that are offered for consideration. First, we pursued a cross-sectional survey; hence, caution is required regarding causality, as the results presented here are related to the cold, dry season (February and March). To better understand seasonal variability, we are in the process of conducting a survey in the same area in the hot, wet season (July and August). Second, the assessment of diarrhoea prevalence was based on caregivers' reports, which may have introduced some recall bias, despite the relatively short recall period of 2 weeks. Third, we did not undertake microbiological analysis of stool samples and drinking water samples, mainly due to budget limitations. Microbiological analysis of drinking water at source and household levels will be conducted in subsequent follow-up studies in the study area.

Despite these limitations, our study provides new insight into the extent of diarrhoea among children under five in Mbour. Our results might be helpful for designing appropriate interventions for preventing childhood diarrhoea in the study area.

\section{Conclusions}

Our study showed that the reported prevalence of diarrhoea among children under the age of five is high in Mbour (26\%), which is similar to previous estimates obtained from DHS. The disaggregated findings provide a useful baseline for more targeted interventions and future studies in more vulnerable urban settings in the area. The study indicates that there is a need for effective preventive measures to reduce the high prevalence of diarrhoea in secondary cities in Senegal. Health intervention programmes, including increasing priority of solid waste and wastewater management, should be introduced and tested, particularly in the PCA and UCA, where diarrhoeal diseases are most common, in order to reduce the prevalence and burden of diarrhoea. The findings also provide useful information to the existing national programme for the fight against diarrhoea and to all other actors developing targeted interventions for preventing childhood diarrhoea.

\section{Additional file}

Additional file 1 Multilingual abstracts in the five official working languages of the United Nations. (PDF $749 \mathrm{~kb}$ )

\section{Abbreviations}

ANSD: National Agency of Statistics and Demography; aOR: Adjusted odds ratio; Cl: Confidence interval; DALY: Disability-adjusted life year; DHS: Demographic and Health Survey; ENSAN: National Survey on Food Security and Nutrition; NPA: North peripheral area; OR: Odds ratio; PCA: Pericentral area; SPA: South peripheral area; UCA: Urban central area; WASH: water, sanitation and hygiene; WHO: World Health Organization

\section{Acknowledgements}

We would like to express our deepest gratitude to the staff of the health facilities of Mbour, as well as to the community members for their kind cooperation and participation in the study survey. Our thanks also go to all the students of the Master "Espaces, Territoires, Populations et Santé" of the Department of Geography at the University of Dakar for their great effort in data collection. We specifically thank the University of Dakar, the University of Basel and the Swiss Tropical and Public Health Institute for supporting this research.

\section{Funding}

This study received financial support from l'Agence Universitaire de la Francophonie and from the Swiss government, through the Swiss Government Excellence Scholarships for Foreign Scholars (ESKAS scholarship) research training at the Swiss Tropical and Public Health Institute, an associated institute of the University of Basel. The funders had a supporting role in the data collection, analysis and preparation of the manuscript.

\section{Availability of data and materials}

The dataset supporting the conclusions of this article are included within the article and its additional files. Moreover, the current dataset contains information not presented here, which might be used for additional analyses. Excerpts from the dataset are available upon request from the corresponding author.

\section{Authors' contributions}

ST, AND, IS, JAN and OF participated in the study conception and design. AND, PV, JU, OF and GC supervised the study. ST is the principal investigator and conducted the data collection activities, managed data entry, cleaned and prepared the database for statistical analysis. ST performed statistical analysis, interpreted the data supported by SF and CS and drafted the manuscript. SF, MSW, JAN, JU and GC revised the manuscript. All authors read and approved the final submitted version of the manuscript.

Competing interests

The authors declare that they have no competing interests.

\section{Consent for publication}

Not applicable.

\section{Ethics approval and consent to participate}

Ethical clearance was obtained from the Comité National d'Ethique de la Recherche (CER) of Senegal (reference number 0 106/2015/CER/UCAD). As the focus of this study was on children under the age of five, written informed consent was obtained from the parents/guardians before commencing the interviews. Participants were free not to answer specific questions or to cease the interview at any time without further obligations. All information gathered was handled confidentially. No biological specimens (stool, urine or blood samples) were collected.

\section{Author details}

${ }^{1}$ Swiss Tropical and Public Health Institute, P.O. BoxCH-4002 Basel, Switzerland. ${ }^{2}$ University of Basel, P.O. BoxCH-4003 Basel, Switzerland. ${ }^{3}$ Département de Géographie, Université Cheikh Anta Diop de Dakar, BP 5005 Dakar, Senegal. ${ }^{4}$ Centre de Suivi Ecologique, BP 15532 Dakar-Fann, Senegal. ${ }^{5}$ Département de Biologie Animale, Université Cheikh Anta Diop de Dakar, BP 5005 Dakar, Senegal.

Received: 24 August 2016 Accepted: 2 June 2017

Published online: 06 July 2017

\section{References}

1. Liu L, Oza S, Hogan D, Perin J, Rudan I, Lawn JE, et al. Global, regional, and national causes of child mortality in 2000-13, with projections to inform post2015 priorities: an updated systematic analysis. Lancet. 2015;385(9966):430-40.

2. Murray CJL, Vos T, Lozano R, Naghavi M, Flaxman AD, Michaud C, et al. Disability-adjusted life years (DALYs) for 291 diseases and injuries in 21 
regions, 1990-2010: a systematic analysis for the Global Burden of Disease study 2010. Lancet. 2012;380(9859):2197-223.

3. Okeke IN. Diarrheagenic Escherichia coli in sub-Saharan Africa: status, uncertainties and necessities. J Infect Dev Ctries. 2009;3(11):817-42.

4. Sire JM, Garin B, Chartier L, Fall NK, Tall A, Seck A, et al. Community-acquired infectious diarrhoea in children under 5 years of age in Dakar, Senegal. Paediatr Int Child Health. 2013;33(3):139-44.

5. MSAS. Recherche formative qualitative sur la prise en charge de la diarrhée a domicile et dans les structures de santé: une analyse du contexte familial et communautaire. In: Ministère de la Santé et de l'Action Sociale du Sénégal (MSAS); 2013. p. 129. (in French).

6. PATH. Infections à rotavirus et vaccins préventifs au Sénégal. In: PATH.org; 2014. (in French).

7. ANSD. Enquête Démographique et de Santé à Indicateurs Multiples 20102011. Dakar: Agence National de la Statistique et de la Démographie (ANSD); 2012. p. 520. (in French)

8. ANSD, ICF International. Sénégal: Enquête Démographique et de Santé Continue (EDS-Continue 2014). Rockville: Agence Nationale de la Statistique et de la Démographie (ANSD) et ICF International; 2015. (in French)

9. ANSD. Recensement général de la population et de l'habitat, de l'agriculture et de l'élevage. In: République du Sénégal, Ministère de l'Economie, des Finances et du Plan; 2014. (in French)

10. Sambe-Ba B, Espie E, Faye ME, Timbine LG, Sembene M, Gassama-Sow A. Community-acquired diarrhea among children and adults in urban settings in Senegal: clinical, epidemiological and microbiological aspects. BMC Infect Dis. 2013;13:580

11. Utzinger J, Keiser J. Urbanization and tropical health-then and now. Ann Trop Med Parasitol. 2006;100(5-6):517-33.

12. Cissé G, Kone M, Bâ H, Mbaye I, Koba K, Utzinger J, Tanner M: Ecohealth and climate change: adaptation to flooding events in riverside secondary cities, West Africa. In: Resilient Cities: Cities and Adaptation to Climate Change Proceedings of the Global Forum 2010, Local Sustainability 1. Edited by (ed.) KO-Z, Springer Science+Business Media B.V; 2011. https:/team.swisstph.ch/ share/proxy/alfresco/api/node/content/workspace/SpacesStore/826ec0008657-4b17-a9a1-1d68b616fbdf/Ciss\%c3\%a9\%20et\%20al. \%20Resilient\%20Cities\%202011.pdf.

13. ONU-HABITAT. The state of African cities 2014: re-imagining sustainable urban transitions. In: ISBN Number (Series): 978-92-1-133397-8. Nairobi: United Nations Human Settlements Programme (UN-Habitat); 2014. p. 278.

14. WHO. Cities and public health crises. Report of the international consultation, Lyon, France. Geneva: World Health Organization; 2009.

15. Costello A, Abbas M, Allen A, Ball S, Bell S, Bellamy R, et al. Managing the health effects of climate change: Lancet and University College London Institute for Global Health Commission. Lancet. 2009:373(9676):1693-733.

16. ANSD. Projection de la population du Sénégal. Dakar: Agence Nationale de la Statistique et de la Démographie; 2012.

17. Gadal S. Systèmes spatio-temporels de suivi de l'urbanisation littorale ouestafricaine et des impacts socio-environnementaux. In: ITP symposium, new horizon of the interdisciplinary approaches to the Asian and African area studies, ASAFAS: 2-3 December 2011; Kyoto University; 2011. p. 5.

18. Toure NM, Kane A, Noel JF, Turmine V, Nedeff V. Water-poverty relationships in the coastal town of Mbour (Senegal): relevance of GIS for decision support. Int J Appl Earth Obs Geoinf. 2011;14(2011):33-9. 7

19. ONAS. Rapport du schéma directeur d'assainissement des eaux usées de la ville de Mbour. Dakar: Office Nationale d'Assainissement du Sénégal; 2008. p. 109.

20. Patel RB, Burke TF. Urbanization-an emerging humanitarian disaster. N Engl J Med. 2009;361(8):741-3.

21. WHO. Diarrhoeal diseases fact sheet: [http://www.who.int/mediacentre/ factsheets/fs330/en/ ]. Accessed 22 Dec 2013.

22. ENSAN. National survey on food security and nutrition (ENSAN) 2013. Dakar: Sécrétariat Exécutif du Conseil National de Sécurité Alimentaire (SECNSA); 2013. p. 14.

23. Touray $\mathrm{S}, \mathrm{Ba} \mathrm{H}, \mathrm{Ba} \mathrm{O}$, Koita M, Salem CB, Keita M, et al. Absence of dry season Plasmodium parasitaemia, but high rates of reported acute respiratory infection and diarrhoea in preschool-aged children in Kaedi, southern Mauritania. Parasit Vectors. 2012;5:193.

24. Koné B, Doumbia M, Sy I, Dongo K, Agbo-Houenou I, Houenou P, Fayomi B, Bonfoh B, Tanner M, Cissé G: Étude des diarrhées en milieu périurbain à Abidjan par l'approche écosanté. VertigO, Hors-série 19 2014. (in French).
25. Sy I, Keita M, Traoré D, Kone B, Bâ K, Wedadi BO, Fayomi B, Bonfoh B, Tanner M, Cissé G: Eau, hygiène, assainissement et santé dans les quartiers précaires à Nouakchott (Mauritanie): contribution à l'approche écosanté à Hay Saken. VertigO, Hors-série 19 | Août 2014. (in French).

26. Bezatu M, Yemane B, Alemayehu W. Prevalence of diarrhea and associated risk factors among children under-five years of age in eastern Ethiopia: a cross-sectional study. Open J Prev Med. 2013;3(7):446-53.

27. Sy I, Keita M, Lo B, Tanner M, Cissé G. Prevalence of infantile diarrhea in districts of Nouakchott (Mauritania) in 2008: analysis of local hygiene. Med Sante Trop. 2012;22(2):217-9.

28. Nitiema LW, Nordgren J, Ouermi D, Dianou D, Traore AS, Svensson L, et al. Burden of rotavirus and other enteropathogens among children with diarrhea in Burkina Faso. Int J Infect Dis. 2011;15(9):e646-52.

29. Siziya S, Muula AS, Rudatsikira E. Correlates of diarrhoea among children below the age of 5 years in Sudan. Afr Health Sci. 2013;13(2):376-83.

30. UNICEF/WHO. Diarrhoea: why children are still dying and what can be done. In: The United Nations Children's Fund (UNICEF)/World Health Organization (WHO); 2009.

31. Mamo A, Hailu A. Assessment of prevalence and related factors of diarrheal diseases among under-five year's children in Debrebirehan referral hospital, Debrebirehan town, north Shoa zone, Amhara region, Ethiopia. Open Access Libr J. 2014;1:e283.

32. Getaneh T, Assefa A, Tadesse Z. Diarrhoea morbidity in an urban area of southwest Ethiopia. East Afr Med J. 1997;74(8):491-4.

33. Osumanu IK. Household environmental and behavioural determinants of childhood diarrhoea morbidity in the tamale metropolitan area (TMA), Ghana. Danish Journal of Geography. 2007;107(1):59-68.

34. Boadi KO, Kuitunen M. Environment, wealth, inequality and the burden of disease in the Accra metropolitan area, Ghana. Int J Environ Health Res. 2005;15(3):193-206.

35. Root GP. Sanitation, community environments, and childhood diarrhoea in rural Zimbabwe. J Health Popul Nutr. 2001;19(2):73-82.

36. Marmot M. The health gap: the challenge of an unequal world. Lancet. 2015;386(10011):2442-4.

37. Marmot M, Bell R. Social inequalities in health: a proper concern of epidemiology. Ann Epidemiol. 2016;26(4):238-40.

38. Tambe AB, Nzefa ID, Nicoline NA. Childhood diarrhea determinants in subSaharan Africa: a cross sectional study of Tiko-Cameroon. Challenges. 2015;6:15.

39. Yilgwan CS, Okolo SN. Prevalence of diarrhea disease and risk factors in Jos University teaching hospital, Nigeria. Ann Afr Med. 2012;11(4):217-21.

40. Yongsi HB. Pathogenic microorganisms associated with childhood diarrhea in low-and-middle income countries: case study of Yaounde - Cameroon. Int J Environ Res Public Health. 2008;5(4):213-29.

41. Gebru T, Taha M, Kassahun W. Risk factors of diarrhoeal disease in underfive children among health extension model and non-model families in Sheko district rural community, southwest Ethiopia: comparative crosssectional study. BMC Public Health. 2014;14:395.

42. Shikur M, Marelign T, Dessalegn T. Morbidity and associated factors of diarrheal diseases among under five children in Arba-Minch district, southern Ethiopia. Sci J Public Health. 2013;1 (2):102-6.

43. Wanzahun G, Bezatu M. Environmental factors associated with acute diarrhea among children under-five years of age in Derashe district, southern Ethiopia. Sci J Public Health. 2013;1(3):119-24.

44. Dessalegn M, Kumie A, Tefera W. Predictors of under-five childhood diarrhea: Mecha district, west Gojam, Ethiopia. Ethiop J Health Dev. 2011; 25(3):192-200.

45. Oloruntoba EO, Folarin TB, Ayede Al. Hygiene and sanitation risk factors of diarrhoeal disease among under-five children in Ibadan, Nigeria. Afr Health Sci. 2014;14(4):1001-11.

46. Girma R. Environmental determinants of diarrhea among under-five children in Nekemte Town, western Ethiopia. Ethiop J Health Sci. 2008:18(2):39-45. 